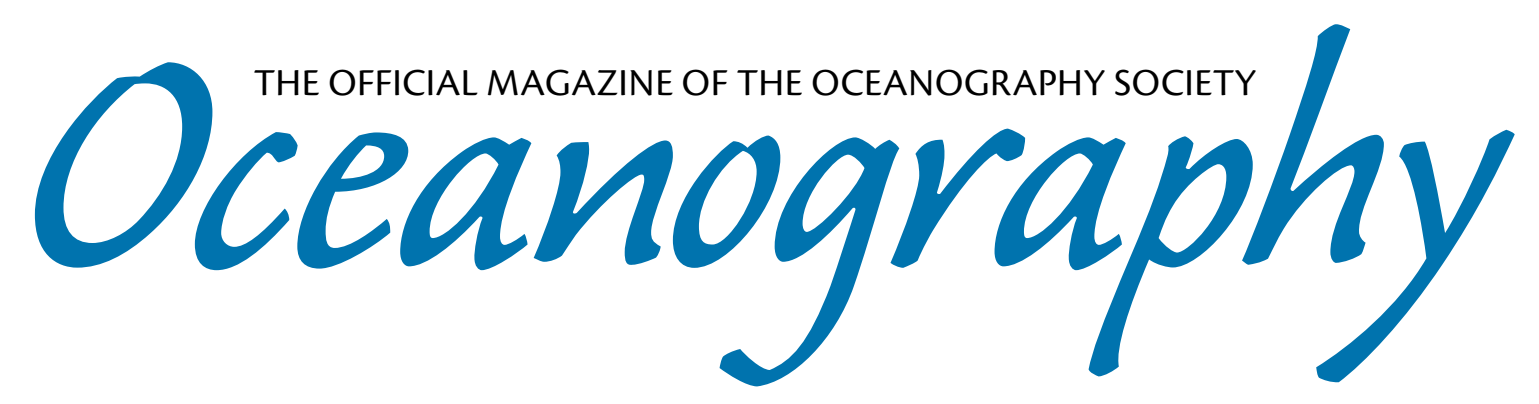

CITATION

Rice, D.L. 2014. What we should know in relation to what we do know. Oceanography 27(1):5, http://dx.doi.org/10.5670/oceanog.2014.27.

DOI

http://dx.doi.org/10.5670/oceanog.2014.27

COPYRIGHT

This article has been published in Oceanography, Volume 27, Number 1, a quarterly journal of The Oceanography Society. Copyright 2014 by The Oceanography Society. All rights reserved.

USAGE

Permission is granted to copy this article for use in teaching and research. Republication, systematic reproduction, or collective redistribution of any portion of this article by photocopy machine, reposting, or other means is permitted only with the approval of The Oceanography Society. Send all correspondence to: info@tos.org or The Oceanography Society, PO Box 1931, Rockville, MD 20849-1931, USA. 


\section{WHAT WE SHOULD KNOW \\ IN RELATION TO WHAT WE DO KNOW}

A little more than four decades ago, in August 1971, the Twentieth Nobel Symposium was convened in Göteborg, Sweden, to address the rising tide of concern about adverse human impacts on the ocean. Although the discussion transcended disciplinary boundaries, the symposium focus was nevertheless on a single theme: The Changing Chemistry of the Ocean. Some 20 years of accelerated industrialization, energy production and consumption, and nuclear proliferation - fortunately, it seems - had been followed by another 20 years of advances in environmental trace metal and radiochemical analytical chemistry. Although the great technological advances in high-performance liquid chromatography and mass spectrometry that would throw open the doors of marine organic geochemistry were still yet to come, the art of environmental trace organic analysis was also making major advances in accuracy and precision, especially with regard to the identification and quantification of pesticide residues. Thanks to this newfound analytical capability, by the time of the symposium, blue-water ocean chemists worldwide were able to see more in seawater than the classic components of sea salt, macronutrients, and dissolved oxygen. The other substances they found always fascinated-and sometimes alarmed-them.

Now, armed with 40 more years of discovery and advancements in marine analytical chemistry, seagoing technology, and geochemical modeling, the contributors to this special issue of Oceanography invite us, a broad scientific and nonscientific readership, to think once again about the causes (anthropogenic or otherwise) and the long-term consequences of changes in the chemistry of the sea. Each author has endeavored to write so that the topic is both thorough and understandable by nonspecialists.
But why do that now? Again? Simply put, I would say that, like our late twentieth century predecessors, we too have benefitted from better chemical and analytical-and modeling-tools that should be brought to the task. Not only that, but these same tools are accelerating our ability to do seawater analyses and make predictions of future ocean chemistry in near-real time. Certainly, in an era of rapid global change, it is no longer acceptable simply to assess the current state of affairs and hope for the best down the road. And we do not have to settle for that. We are getting better and better at doing much, much more. Whether we are scientists, educators, policymakers, or just concerned citizens, this is something that we all need to know about.

Five years after the Nobel Symposium, in the Introduction to his The Health of the Oceans, Edward Goldberg, one of the Nobel Symposium planners, posed the rhetorical question, "Why another book on marine pollution?" I think that his apologia for his own book would apply equally, if not with greater urgency, to this special issue: rather than just compiling an inventory of the components of seawater, there is "the more formidable problem of asking what we should know, in relation to what we do know, about the alteration of the ocean's chemistry by man, in order to regulate the releases of materials to the ocean."*

Donald L. Rice

Chemical Oceanography Program

National Science Foundation

*E.D. Goldberg. 1976. The Health of the Oceans. The UNESCO Press, Paris, 172 pp. 